\title{
Cities in Relations: Trajectories of Urban Development in Hanoi and Ouagadougou
}

\author{
S. D. Wolfe \\ Department of Geography, University of Zurich, Zurich, Switzerland \\ Correspondence to: S. D. Wolfe (dwolfe@geo.uzh.ch)
}

Söderström, O.: Cities in Relations: Trajectories of Urban Development in Hanoi and Ouagadougou, Oxford, WileyBlackwell, 230 pp., ISBN-13 978-1-118-63280-2, €33.00, 2014.

For many socialist and communist nations, the fall of the Soviet Union spelled the end of critical support and, in numerous cases, marked the beginning of a historic transition to political and economic liberalism. Traditionally, this transition has been analyzed in the domains of political economy or post-colonial studies. Ola Söderström's Cities in Relations represents a strong blow against this reductionist trend and endeavors to create a deeper understanding of the "transition from socialism" by examining urban change in two cities of the Global South. He develops a relational framework to compare the trajectories of change in Hanoi and Ouagadougou since 1990, focusing on how the policies, urban forms, and urban practices in each city are shaped by their relations with "elsewhere". His process results in a richer and more nuanced picture of urban development in the Global South and provides scholars with a novel set of conceptual tools for future research.

At its heart, Cities in Relations is a story of two cities reconnecting with global flows. Söderström tracks developments in the capital cities of Vietnam and Burkina Faso ranked among the least-developed countries of the world as they undergo significant political and economic reforms in their transition to a neoliberal system. But Söderström aims to go beyond traditional ranking-based explanations of urban development and globalization, moving towards an assetsbased analysis built with an appreciation of the complex and far-reaching effects inherent in the web of relations that shapes urban development. By examining the intensity, form, and orientation of global connectivity in each city over time, Söderström finds a fundamental difference between their development trajectories, one that would easily be lost in a less detailed exploration: Hanoi boasts superior connections to economic flows, whereas Ouagadougou has established greater connections to political flows. This key divergence goes a long way towards explaining the differing development projects in each city that Söderström explores in later chapters.

From the outset, then, this understanding moves the discussion of the transition from socialism beyond a typical political-economic vocabulary. Investigating the flows of capital, people, and information allows Söderström to highlight what he calls the "emergence of new geopolitics of urban relations" (p. 55), bringing the conversation to a deeper, more subtle place. He then places this conversation into the wider context of the Global South turning away from Europe and North America as providers of models of urban development and reorienting toward South-South or East-East relations.

Söderström begins the book with a general overview of his theoretical grounding and overall goals. He then launches into the meat of the text: a broad-strokes review of each city's recent political history followed by a progression through a series of theoretical explorations and practical examples of policy brought to life in the streets. Every chapter introduces a particular set of concepts and then investigates the realization of these concepts in the subject cities, illustrated with the help of concrete projects on the ground. These include the specific local contexts of urban planning and the making of policy of public space in general, the construction of an elite housing development, a farmer's market, a new highway interchange, and an upscale shopping mall.

What emerges is a picture of Söderström's methodological concepts illuminated, as it were, from two sides, via real-life projects in both Hanoi and Ouagadougou. This strategy is successful at bringing to light the more problematic and contradictory aspects of relationally produced policies. In this way, Söderström does a good job at explaining why, for instance, policies created for the specific contexts of London or Lyon may not always translate well to the vastly differ- 
ent worlds of Hanoi or Ouagadougou. If there is a problem with this conceit, it is that the specific examples in each city may not be immediately comparable. It would be nice, for instance, to pair the failed farmer's market attempt in Ouagadougou with a similar farmer's market project in Hanoi. Of course, ideal direct comparisons are not always available, so Söderström fits assorted real-world examples underneath a broader conceptual umbrella. This is a good work-around solution, but still the idea of perfect parallel projects in comparative perspective is an alluringly poetic idea. This speaks to the fact that Söderström is at his best when exploring the ground in Hanoi and Ouagadougou - he has a keen eye for finding compelling projects to examine - and his book could only benefit from more concrete demonstrations of his conceptual ambitions in practice.

On the conceptual and methodological side of the spectrum, Söderström makes a strong case for using actornetwork theory to underpin a relational approach to understanding post-colonial development, policy mobility, and the nature of power. This, he argues, is critical to creating a broader understanding of a city's relational world, itself a key ingredient in building a better politics of urban relatedness. With this in mind, Söderström's choice of subject - two "relation-poor" cities - is particularly clever. After all, the web of connections in a more prominent city would likely be significantly harder to untangle and analyze, whereas it is still reasonably plausible to get a grasp of the more modest relational world of his chosen cities. This dovetails neatly into Söderström's point that all cities are world cities, and overall this book represents a convincing argument for more attention focused on the Global South.

Söderström painstakingly traces the translocal connections involved in the making of public space policy and examines the results as they are implemented on the ground. Continuing on the thread of actor-network theory and policy mobility, this investigation of the creation and application of public space policy represents the epicenter of the entire work. This takes place in the specific and very local cultural and historical contexts of the subject cities, and Söderström is quite right to discuss how these local specificities profoundly influence topological relations in order to assemble a coherent policy. The time spent building a solid contextual and methodological grounding allows Söderström to explain extremely specific local results, including the meaning of $l e$ goudron - asphalt - on Ouagadougou's streets, or the culturally normal appropriation of sidewalk spaces in Hanoi. These local characteristics have profound effects on the implementation of projects and make it impossible for policies to travel smoothly from north to south. With the skill of a forensic scientist, Söderström explores the multiple layers of meaning of public space in these post-colonial cities and successfully explains how policies mutate and why some of them succeed while others fall flat.
With a clear, logical structure and a foundation of rigorous methodology, Söderström examines urban policy, form, and production in order to build a new and more fluid conception of relatedness with "elsewhere". He succeeds in furthering the discussion on urban development in the Global South, providing concrete examples that policies cannot simply be "transposed" into new contexts. Indeed, Cities in Relations as a whole represents a compelling argument for a broader, more nuanced conception of a city's web of relations. This is a cogent, well-organized text that keeps the reader grounded while exploring new conceptual territories in unique and concrete spaces. It would be interesting to carry this work further and analyze other less-prominent cities with the tools Söderström has forged in Hanoi and Ouagadougou. Aside from the obvious choices in Southeast Asia and sub-Saharan Africa, there exist a number of interesting potential candidate cities for future study among the emerging cities in Central Asia. This would be especially valuable in continuing the study of urban developments in the post-communist environment. In Cities in Relations, Söderström not only explains the postcommunist, post-colonial development of Hanoi and Ouagadougou; he makes a solid argument for the importance of examining the world's less-prominent cities more broadly. 